\title{
CLASS 2 MALOKLÜZYONUN LAMİNATE VE TAM SERAMİK RESTORASYONLAR İLE REHABİLİTASYONU: VAKA SUNUMU ${ }^{\ddagger}$
}

\section{REHABILITATION WITH LAMINATE AND FULL CERAMIC RESTORATIONS OF ANGLE CLASS II MALOCCLUSION: A CASE REPORT ${ }^{\nexists}$}

\author{
Dt. Büşra TOSUN*
}

Prof Dr. Nuran YANIKOĞLU*

\author{
Makale Kodu/Article code: 4010 \\ Makale Gönderilme tarihi: 07.03.2019 \\ Kabul Tarihi: 13.01 .2020
}

DOI: $10.17567 /$ ataunidfd.674142

\section{öz}

Ortodontik anomalilerin yaklaşık 1/3'ünü oluşturan sınıf 2 maloklüzyonlar gerek klinik görüntüleri gerekse tedavi seçenekleri açısından çeşitlilik göstermektedir. Bu vakada, metal destekli porselen köprülere kıyasla ışık geçirgenliği iyi olduğundan, renk ve form açısından daha doğal olan, protetik açıdan da yüksek dayanıklıık ve estetiğe sahip tam seramik uygulaması tercih edildi. Ağzında mevcut eski kuronlarındaki estetik görüntü sikâyeti ile Atatürk Üniversitesi Protetik Diş Tedavisi Anabilim Dalına başvuran 23 yaşındaki kadın hastaya ortodontik tedaviyi kabul etmediğinden alternatif tedavi seçeneği olarak protetik planlama yapıldı. Öncelikle maksiller sağ lateral ve sol santral dişlerinin vestibüle doğru olan aksları olması gereken açıdan fazla olduğundan bu dişlere kanal tedavisi yapıldı, maksiller sol santral dişe fiber post ve kompozit uygulandı. Daha estetik bir gülüş yakalamak amacıyla, maksiller sağ ve sol kanin dişlerde, mevcut herhangi bir çürük veya şekil bozukluğu olmadığından laminate kuron olarak prepare edildi, maksiller sağ santral ve lateral ile sol santral ve lateral dişler ise tam seramik kuron preparasyonuna uygun olarak shoulder basamak frezi ile prepare edilip silikon ölçü materyali ile daimî ölçüleri alındı. IPS E.max cam seramik restorasyonlar laboratuvarda hazırlandı ve rezin siman ile simante edildi.

Maloklüzyonların tedavisinde protetik rehabilitasyon, hasta ortodontik tedaviyi kabul etmediği durumda alternatif tedavi seçeneklerinden biridir. Lityum disilikat ile güçlendirilmiş seramik restorasyonlarla yapılan tedavi sonrasında estetik ve fonksiyon açısından başarılı sonuçlar elde edilmiş, kontrollerde hasta memnuniyeti sağlanmıştır.

Anahtar Kelimeler: Maloklüzyon, Laminate, Seramik restorasyon, Protetik rehabilitasyon

\section{ABSTRACT}

Class 2 malocclusions, which constitute about $1 / 3$ of orthodontic anomalies, vary in terms of clinical images and treatment options. In this case it was preferred to use a full ceramic application in which we can obtain more natural color and form, which has a good aesthetic appearance and durability.

A 23-year-old female patient applied to the department of the prostodontics at Atatürk University Faculty of Dentistry with a complaint in the old crowns. Since she did not accept orthodontic treatment, prosthetic planning was performed as an alternative treatment option. Firstly, because the axes of the maxillary right lateral and left central teeth towards the vestibule were more than necessary canal treatment was performed. Fiber post and composite were applied to the maxillary left central tooth. In order to achieve a more aesthetic smile, the maxillary right and left canine teeth were prepared as laminate crowns because there were no caries, deformations or discolorations. Maxillary incisive teeth were prepared with shoulder step drill in accordance with full ceramic crown preparation.

Prosthetic rehabilitation in the treatment of malocclusions is one of the alternative treatment options if the patient does not accept orthodontic treatment. After the treatment with lithium disilicate reinforced ceramic restorations, successful results were obtained in terms of aesthetics and function, in the controls patient satisfaction was achieved.

Key words: Malocclusion, Laminate, Ceramic Restoration, Prosthetic rehabilitation

\footnotetext{
\begin{tabular}{l}
${ }^{*}$ Atatürk Üniversitesi Diș Hekimliği Fakültesi Protetik Diș Tedavisi AD. Erzurum \\
\hline B Bu makale 2-4 Kasım 2018 tarihinde 6. Uluslararası Türk Prostodonti ve İmplantoloji Derneği Dicle Sempozyumun'nda
\end{tabular} poster olarak sunulmuştur.
}

Kaynakça Bilgisi: Tosun B, Yanıkoğlu N. Class 2 Maloklüzyonun Laminate ve Tam Seramik Restorasyonlar İle Rehabilitasyonu: Vaka Sunumu. Atatürk Üniv Diş Hek Fak Derg 2020; 30: 476-80.

Citation Information: Tosun B, Yanikoglu N. Rehabilitation With Laminate and Full Ceramic Restorations of Angle Class II Malocclusion: A Case Report. J Dent Fac Atatürk Uni 2020; 30: 476-80. 


\section{GİRİŞ}

Diş hekimliğinde yaygın olarak kullanılan restorasyonlardan biri, metal destekli seramik restorasyonlardır. Bu restorasyonlar estetik özelliğini yüksek geçirgenliğinden ve doğal görünümlü olan porselenden almakla birlikte, dayanıklıı̆ını ise metal alt yapıdan almaktadırlar. ${ }^{1}$ Metal seramik restorasyonların, yüksek dayanıklılık, metal alt yapı dolayısıyla streslere karşı koyabilme gücü, Isısal uyum, çatlak oluşma riskinin az olması ve kırılmaya karşı direncinin fazla olması gibi birçok avantajı bulunmaktadır. Metal seramik restorasyonlar diş hekimliğinde rutin olarak kullanılmasına ve birçok avantajı olmasına rağmen çoğu vakada estetiği yeterince sağlamak mümkün olmamaktadır. ${ }^{2}$

Metal alt yapı nedeniyle porselen kalınlığının yetersiz kalabilmesi, özellikle dişeti biyotipi ince olan hastalarda servikal ön bölgede grimsi metal renk yansıması, diş eti çekilmesi gözlenen vakalarda metalin açığa çıkabilmesi, porselen metal bağlantısında oluşan oksit tabakasına bağlı bazı problemler gözlenebilmesi gibi birtakım dezavantajları da vardır. ${ }^{3,4} \mathrm{Bu}$ tür dezavantajlarından dolayı günümüzde metal alt yapı içermeyen, çeşitli yöntemlerle güçlendirilmiş çok sayıda tam seramik sistemi geliştirilmiştir. ${ }^{5}$

Tam seramik restorasyonlar estetik olmaları, yüksek mekanik özellikleri ve biyouyumluluğundan dolayı hem hastalar hem de diş hekimleri tarafından oldukça sık tercih edilen restorasyonlardandır. ${ }^{6}$ Özellikle kuron, köprü, inley, onley ve post yapımında kullanılmasının yanısıra implant, abutment ve ortodontik braket olarak da kullanılabilen zirkonyum tam seramik restorasyonlar, yüksek kırılma ve gerilme direncine sahiplerdir. ${ }^{7,8}$ Tercih edilmelerindeki en önemli nedenlerden biri de estetik özelliklerinin yanı sıra biyouyumlu materyaller olmalarıdır. ${ }^{9,10}$

Metal destekli restorasyonlara göre ISı ve elektrik iletkenlikleri daha az olduğundan ${ }^{11}$ termal hassasiyetleri azaltması ${ }^{12}$, üstün dişeti cevabı oluşturmaları, alaşıma bağlı korozyon, toksisite ve alerjik reaksiyon gözlenmemesi, X ışınına karşı geçirgen olduğundan dolgu ve kuron altındaki dişin kök kanalının rahatlıkla gözlenmesine olanak sağlaması, alt yapı ile mükemmel bir şekilde birleştiği için metalde olduğu gibi çatlak ve ayrılma görülmemesi, gelen ışık büyük miktarda kuron içinden geçebildiğinden görünümünün doğal dişe yakın olması diğer olumlu özelliklerindendir. ${ }^{13,14}$

Tam seramik restorasyonların yanısıra diş dokusunu olabildiğince koruyan tedavi seçeneklerinden biri olan laminate veneerler ise özellikle anterior dişlerde uygulanan, minimal diş preparasyonu gerektiren, dişin labial yüzeyine ince bir restoratif materyalin uygulanması ile elde edilen restorasyonlardır. ${ }^{15}$

Estetik özelliklerinin iyi olması, renk stabilitesi, kompozitlere kıyasla yüksek abrazyon direnci göstermesi, çok az miktarda diş dokusundan kesim gerektirmesi veya hiç kesim yapmadan da uygulabilmesi, mine dokusuna güvenli bir şekilde ve yeterli miktarda bağlanması porselen laminate veneerlerin en önemli avantajlarındandır. ${ }^{16}$

Mine hipoplazisi ve malformasyonları, diastemaların kapatılması, diş renklenmeleri, erozyona uğramış, malpoze veya rotasyonel dişler, klinik kuron boyu kısa olan dişlerin uzatılması laminate veneerlerin endikasyonlarındandır. ${ }^{17}$ Bunların dışında porselen laminate veneerler, Class 2, Class 3 gibi maloklüzyonu olan veya dişlerinde çapraşıklığı bulunan hastalardaki estetik görüntünün ve kaybolan fonksiyonun kazandırılmasında sınırlı da olsa kullanılmaktadırlar.

Bu çalışmada maksilla anterior bölgede estetik görüntü şikayetiyle kliniğimize başvuran Class II maloklüzyonu olan hastanın ortodontik tedaviyi kabul etmediğinden IPS E.max Press lityum disilikat ile güçlendirilmiş cam seramik ile protetik rehabilitasyonu anlatılmıştır.

\section{VAKA SUNUMU}

Atatürk Üniversitesi Diş Hekimliği Fakültesi Protetik Diş Tedavisi Anabilim dalına estetik problemlerle başvuran hastanın, öncelikle klinik ve radyolojik muayenesi yapıldı. Yapılan radyolojik muayenede maksiller sağ santral dişinin kanal tedavili ve maksiller sağ ve sol santral dişlerinde kuronların mevcut olduğu görüldü. (Resim 1) Klinik muayenede ise maksiller ve mandibular anterior dişler arasında $4.5 \mathrm{~mm}$ overjet ile sonuçlanan Class 2 maloklüzyonu olduğu görüldü. (Resim 2 ve 3) Hastaya ilk olarak ortodontik tedavi seçeneği sunuldu fakat Tip 1 diabeti olduğundan tedavi sonucu kemik kaybı görülebileceği ve iyileşmede gecikme gözlenebileceği söylendiğinde hasta bu tedavi seçeneğini kabul etmedi ve hastanın protetik olarak rehabilite edilmesine karar verildi. Yapılabilecek tedavi seçenekleri hastaya sunuldu ve hastadan bilgilendirilmiş onam formu alınarak tam seramik restorasyon yapılmasına karar verildi.

İlk olarak maksiller sağ lateral ve maksiller sol santral dişlerin normal açıda konumlandırılabilmesi ve estetik bir şekilde protetik açıdan tedavi edilebilmesi için bu dişler endodontik olarak tedavi edildi. Maksiller sol santral dişteki madde kaybı fazla olduğundan ve yapılacak tam seramik sonrası seramik altından 
herhangi bir renk yansıması olmaması için bu diş fiber post uygulaması sonrası kompozit ile restore edildi.

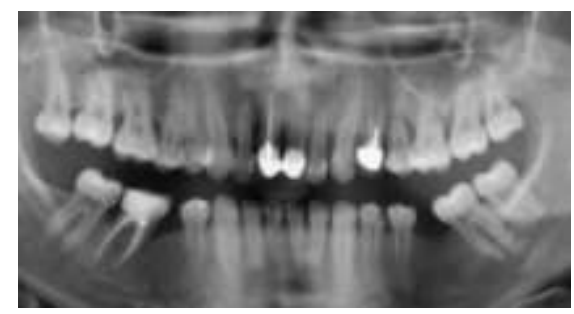

Resim 1. Hastanın başlangıç radyografı

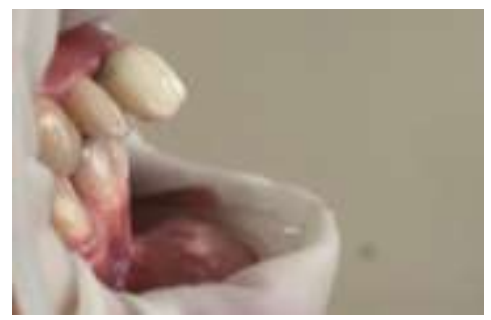

Resim 2. Sagital düzlemde başlangıç görünüm

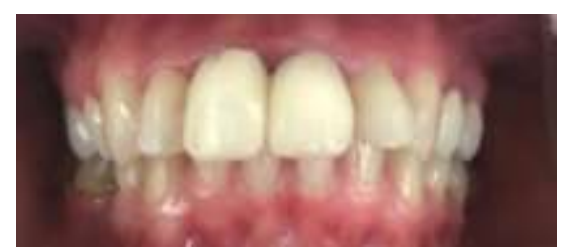

Resim 3. Frontal düzlemde başlangıç görünü

Maksiller sağ santral, lateral ile sol santral, lateral dişler tam seramik kuron preparasyonuna uygun olarak shoulder basamak frezi ile serbest dişeti kenarının $0.5 \mathrm{~mm}$ altında olacak şekilde prepare edildi. Hasta isteğiyle daha estetik bir gülüş yakalamak amacıyla maksiller sağ ve sol kanin dişler ise laminate kuron olarak prepare edildi. Preparasyon sonrası tüm keskin kenar ve köşeler yuvarlatıldı. (Resim 4) Basamak bölgesinin net olarak ölçüye yansıtılabilmesi için retraksiyon ipi ile (Ultrapak, Ultradent, South Jordan, USA) dişeti retraksiyonu yapıldı ve additional silikon ölçü maddesiyle (Elite HD, Zhermack, Badia Polesine, Italy) daimî ölçüsü alındı.

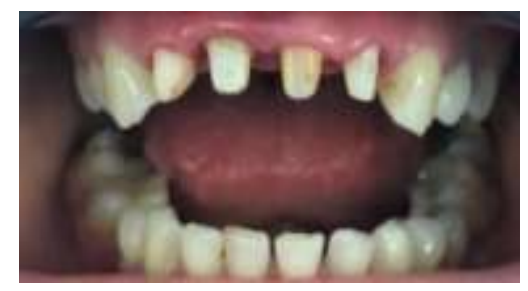

Resim 4. Preparasyon sonrası ağız içi görünüm
Tam seramik kuronlar ve porselen laminate veneerler lityum disilikat ile güçlendirilmiş IPS E.max porselenden presleme tekniği ile elde edilmiş olup bitmiş veneerlerin ağız içinde gerekli uyumlamaları yapılarak simantasyon işlemine geçildi. Panavia V5 rezin siman setinde mevcut olan $\mathrm{K}$ Etchant Syringe ile 5 saniye restorasyon iç yüzeyleri fosforik asit ile pürüzlendirildi, yıkandı ve kurutuldu. Porselen ile rezin siman arasındaki bağlantıyı güçlendirmek için restorasyonların iç yüzeyine Clearfill ceramic primer plus uygulandı. Sonrasında kurutularak restorasyonlar yapıştırma işlemine hazır hale getirildi ve diş yüzeyindeki işlemlere başlandı. Prepare edilen dişler pomza ve lastik yardımı ile polisajlandı, rulo pamuklarla izole edildi. Diş eti sıvısının gingival bölgeye sızmasını engellemek ve yapıştırma işlemi sırasında marjinal bölgenin daha net gözlenebilmesi için dişeti retraksiyon ipleri yerleştirildi. Dişlerin interproksimal kontakları teflon bantlar ile komşu dişlerden izole edildi. Prepare edilen dişlere $\mathrm{K}$ Etchant Syringe ile 10 saniye fosforik asit uyguland, yıkandı ve kurutuldu, asit uygulaması ardından Panavia V5 tooht primer 20 saniye uygulandı ve kurutuldu. Sonrasında rezin siman (Panavia V5, Kuraray Medical, Tokyo, Japan) restorasyon içine uygulanarak kuronlar yerleştirildi, polimerizasyon öncesi artık siman küçük bir bond fırçası ile uzaklaştırıldı ve restorasyonlar üretici firmanın önerileri doğrultusunda her yüzeyden ışıklandı. Teflon bantlar ara yüzeylerden çıkarılarak artikülasyon kâğıdı ile oklüzyon kontrolü yapıldı. Hastaya protezlerinin temizliği ve bakımı ile ilgili oral hijyen eğitimi verildi ve düzenli olarak aylık kontrollere çağırıldı. 3 ay sonra kontrole geldiğinde dişeti sağlığı ile protezinin estetik ve fonksiyonel yönden iyi durumda olduğu belirlendi.

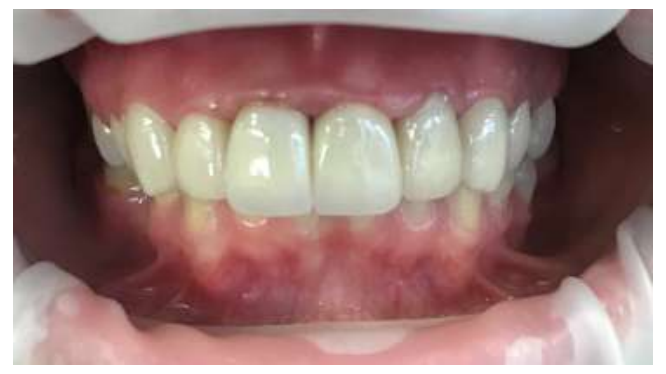

Resim 5. Simante edilmiş restorasyonların ağız içi görünümü 


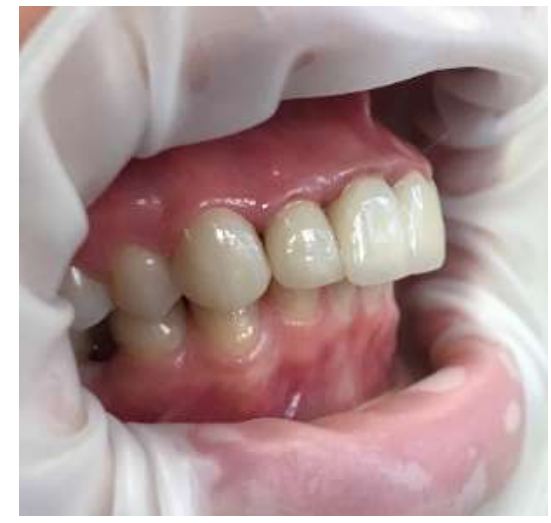

Resim 6. Bitmiş restorasyonların sagital cepheden görünümü

\section{TARTIŞMA}

Günümüzde metal seramik restorasyonlar sıklıkla kullanılmasına karşı estetik görünüme artan talep hem hastaları hem de diş hekimlerini özellikle daha estetik olan tam seramik materyallere yönlendirmiştir. ${ }^{18}$ Tam seramik restorasyonların ışık geçirgenliği daha iyi olduğundan estetik açıdan metal seramik restorasyonlardan daha üstündür. ${ }^{19}$ Bununla birlikte porselen kor yapı içerisine titanyum oksit, zirkonyum oksit ve seryum oksit gibi çeşitli renk pigmentlerinin ilave edilmesi porselenin ışık geçirgenliğini etkilemektedir. ${ }^{20}$

Kırılma ve gerilme direnci açısından yüksek değerlere sahip olan tam seramikler aynı zamanda oldukça biyouyumlu materyaller olup, yapılan uzun dönem takiplerde klinik açıdan da başarılı oldukları rapor edilmiştir. ${ }^{21,22}$

Bir tam seramik restorasyonun başarısı doğru vaka seçimi, diş preparasyonu, kullanılan materyalin uygulanma şekli ve simantasyon gibi birçok faktöre bağlıdır. ${ }^{5}$ Tam seramik sistemlerinden özellikle cam infiltre seramikler kullanılıyorsa simantasyon işleminde mutlaka adeziv simanlar tercih edilmelidir. ${ }^{23,24}$ Mc Cormick ve arkadaşlarının yaptığı çalışmada olduğu gibi mekanik özellikleri zayıf olan cam infiltre seramiklerin bu şekilde yapılan simantasyon işleminden sonra kırıma dayanımını artırdığı sonucuna ulaşıımıştır. ${ }^{25}$

Günümüzde en çok tercih edilen restorasyon tiplerinden olan tam seramik restorasyonların ışık geçirgenliğinin ve renk uyumunun doğal dişe oldukça yakın olması klinik kullanımlarını artırmıştır. Fakat kırılganlık dezavantajı hala tam olarak giderilememiştir.

Zortuk ve arkadaşları ${ }^{26}$, bizim çalışmamıza benzer olarak maloklüzyonu olan bir hastaya protetik restorasyon planlamışlardır. Sınıf 3 Çapraz kapanışı düzeltmede ortodontik tedavi yapılabileceğini fakat bu tedavi şeklinin uzun sürmesi, rahatsızlık vermesi ve estetik olmayan görüntüsü dolayısıyla hastanın bu tedavi yaklaşımını tercih etmediğini bildirmişlerdir. İlk aşamada, azalmış oklüzal dikey boyuta sahip hastaya, overlay protez kullandırtarak, yeni oklüzal dikey boyut oluşturmuşlar, bunun ardından 6 aylık adaptasyon sürecinin sonunda alt ve üst çeneye metal destekli porselen restorasyonlar yapmışlardır.

Farklı bir çalışmada da Saadet ve arkadaşları ${ }^{17}$ Class III kapanışı olan, ortognatik cerrahi ve ortodontik tedavi seçeneklerini kabul etmeyen bir hastaya protetik olarak tam seramik kuron ya da metal destekli porselen kuron yerine estetik ve en konservatif restorasyon tipi olan porselen laminate veneer uygulaması yaparak hastanın estetik ve fonksiyonel ihtiyaçlarını karşılamaya çalışmışlardır. Tedavi sonrası hastanın kontrol randevusunda, bizim çalışmamızda olduğu gibi, restorasyonlarda kırılma ya da dişten ayrılma durumu gözlenmediğini bildirmişlerdir. Sonuç kısmında yine çalışmamıza paralel olarak malokluzyonların düzeltilmesinde ortodontik tedaviye alternatif olarak protetik rehabilitasyonun, hastanın estetik ve fonksiyonel ihtiyaçlarını gidermede tercih edilebilecek seçeneklerden biri olduğunu belirtmişlerdir.

Vakamızda ortodontik tedavi gereksinimi olan fakat tedaviyi kabul etmeyen hastaya üst anterior kanin dişlerine laminate, keser dişlerine ise cam infiltre tam seramik restorasyon yapılarak artmış overjet düzeltilmeye çalışılmış ve 1 yıl sonra kontrol randevusuna çağrıldığında hastamız şehir değişikliği yaptığı için kliniğimize gelemediğinden kontrol fotoğrafı alınamamış olup sözel olarak restorasyonlarda kırılma, çatlama ya da herhangi bir şikayetinin olmadığını belirtmiştir.

NOT: Calışmada herhangi bir yazar, kurum ya da kuruluş ile çıkar çatışması içerisinde bulunmamaktadır. Makale daha önce hiçbir yerde yayınlanmamıştır ve yayınlanmak üzere işlem görmemektedir.

\section{KAYNAKLAR}

1. Özcan M, Niedermier W. Clinical study on the reasons for and location of failures of metalceramic restorations and survival of repairs. Int J Prosthodont 2002;15(3):299-302.

2. Hasssija J, Hegde V, Sridhar N. An in vitro study on effect of ceramic thickness and multiple firings on colour of metal ceramic restorations. The Journal of Indian Prosthodontic Society 2014;14(1):86-92.

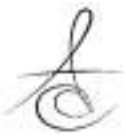


3. Beuer F, Edelhoff D, Gernet W, Naumann M. Hazırlama açılarının CAD / CAM sistemi tarafından üretilen zirkonya taç kopinglerinin hassasiyeti üzerindeki etkisi. Dişçilik Malzemeleri Derg 2008; 27: 814-20.

4. Manicone PF, Iommetti PR, Raffaelli L. An overview of zirconia ceramics: basic properties and clinical applications. Journal of dentistry. 2007;35:819-26.

5. Toman M, Toksavul S, Firidinoglu K. Tüm seramik restorasyonlar ve klinik uygulaması: olgu sunumu. Cumhuriyet DenT J 2011;11:49-52.

6. Takeichi T, Katsoulis J, Blatz MB. Clinical outcome of single porcelain-fused-to-zirconium dioxide crowns: a systematic review. J Prosthet Dent 2013;110:455-61.

7. Denry I, Kelly JR. State of the art of zirconia for dental applications. Dent Material 2008;24:299307.

8. Al-Amleh B, Lyons $K$, Swain M. Clinical trials in zirconia: a systematic review. J Oral Rehabil 2010; 37:641-52.

9. Dundar M, Gungor MA, Cal E. Multidisciplinary approach to restoring anterior maxillary partial edentulous area using an IPS Empress 2 fixed partial denture: A clinical report. J Prosthet Dent 2003; 89:327-30.

10. Toksavul S, Ulusoy M, Toman M. Clinical application of all-ceramic fixed partial dentures and crowns. Quintessence international. 2004;35(3).

11. Macit ŞN, Oruç S, Gürbüz A, Kılıçarslan MA. Farklı Seramik Kor Yapılarının Veneer Porselen Rengi Üzerine Etkilerinin Değerlendirilmesi. AÜ Diş Hek Fak Derg 2016;43:157-64.

12. Raigrodski AJ. Contemporary all-ceramic fixed partial dentures: a review. Dent Clin North Am 2004; 48:viii,531-44.

13. Korkmaz C. Tam Seramiklerin Dişhekimliğindeki Yeri. Atatürk Üniversitesi Diş Hekimliği Fak Derg 2015; 24(:136-40

14. Boening $\mathrm{KW}$, Wolf $\mathrm{BH}$, Schmidt $A E$, Kästner $K$, Walter $\mathrm{MH}$. Clinical fit of Procera AllCeram crowns. J Prosthet Dent 2000;84:419-24.

15. Gürel G. The science and art of porcelain laminate veneers: London: Quintessence; 2003. p. 34.

16. Edelhoff D, Sorensen JA. Tooth structure removal associated with various preparation designs for anterior teeth. J Prosthet Dent 2002;87:503-9.

17. Saadet A. Anterior Bölgede Sınıf III Maloklüzyonun Porselen Laminate Veneerlerle Tedavisi: Olgu Sunumu. KÜ TIp Fak Derg 2011;13:39-41.
18. Pollington S. Novel glass-ceramics for dental restorations. J Contemp Dent Pract. 2011;12:60-7.

19. Castellani D, Baccetti T, Giovannoni A, Bernardini UD. Resistance to fracture of metal ceramic and all-ceramic crowns. Int J Prosthodont 1994;7:14954.

20. O'Brien WJ. Dental Materials and Their Selection; Quintessence Pub. Co: Chicago, IL, USA. 2002;23.

21. Zimmer D, Gerds T, Strub JR. Survival rate of IPSEmpress 2 all-ceramic crowns and bridges: three year's results. Schweiz Monatsschr Zahnmed 2004;114:115-9.

22. Toksavul S, Toman M. A short term clinical evaluation of IPS Empress 2 crowns. Int J Prosthodont 2007;20:168-72.

23. Behr M, Rosentritt M, Mangelkramer M, Handel G. The influence of different cements on the fracture resistance and marginal adaptation of all-ceramic and fiber-reinforced crowns. Int J Prosthodont 2003; 16:538-42.

24. Janda $R$, Roulet JF, Wulf M, Tiller HJ. A new adhesive technology for all-ceramics. Dent Mater 2003;19:567-73.

25. McCormick JT, Rowland W, Shillingburg HT, Duncanson MG. Effect of luting media on the compressive strengths of two types of all-ceramic crowns. Quintessence Int 1993;24:405-8.

26. Zortuk M, Özen J, Sipahi C. Ön Derin Çapraz Kapanışla Birlikte Görülen Sınıf III Maloklüzyonun Protetik Tedavisi: Olgu Raporu Prosthetic Treatment of A Class III Malocclusion Combined with Anterior Deepbite: A Case. Hacettepe Dişhek Fak Derg 2006;30:60-4.

\author{
Yazışma Adresi \\ Dt. Büşra Tosun \\ Atatürk Üniversitesi, Diş Hekimliği Fakültesi \\ Erzurum, Türkiye \\ Tel: 05056142848 \\ Mail: dtbusra86@hotmail.com
}

